\title{
Quetiapine versus haloperidol in the treatment of delirium: a double-blind, randomized, controlled trial
}

This article was published in the following Dove Press journal:

Drug Design, Development and Therapy

23 July 2013

Number of times this article has been viewed

\author{
Benchalak Maneeton' \\ Narong Maneeton' \\ Manit Srisurapanont ${ }^{1}$ \\ Kaweesak Chittawatanarat ${ }^{2}$ \\ 'Department of Psychiatry, \\ ${ }^{2}$ Department of Surgery, Faculty \\ of Medicine, Chiang Mai University, \\ Chiang Mai, Thailand
}

Background: Atypical antipsychotic drugs may have low propensity to induce extrapyramidal side effects in delirious patients. This study aimed to compare the efficacy and tolerability between quetiapine and haloperidol in controlling delirious behavior.

Methods: A 7-day prospective, double-blind, randomized controlled trial was conducted from June 2009 to April 2011 in medically ill patients with delirium. Measures used for daily assessment included the Delirium Rating Scale-revised-98 (DRS-R-98) and total sleep time. The Clinical Global Impression, Improvement (CGI-I) and the Modified (nine-item) SimpsonAngus Scale were applied daily. The primary outcome was the DRS-R-98 severity scores. The data were analyzed on an intention-to-treat basis.

Results: Fifty-two subjects ( 35 males and 17 females) were randomized to receive $25-100 \mathrm{mg}$ /day of quetiapine $(\mathrm{n}=24)$ or $0.5-2.0 \mathrm{mg} /$ day of haloperidol $(\mathrm{n}=28)$. Mean (standard deviation) doses of quetiapine and haloperidol were $67.6(9.7)$ and $0.8(0.3) \mathrm{mg}$ /day, respectively. Over the trial period, means (standard deviation) of the DRS-R-98 severity scores were not significantly different between the quetiapine and haloperidol groups ( -22.9 [6.9] versus -21.7 [6.7]; $P=0.59$ ). The DRS-R-98 noncognitive and cognitive subscale scores were not significantly different. At end point, the response and remission rates, the total sleep time, and the Modified (nine-item) Simpson-Angus scores were also not significantly different between groups. Hypersomnia was common in the quetiapine-treated patients (33.3\%), but not significantly higher than that in the haloperidol-treated group (21.4\%).

Limitations: Patients were excluded if they were not able to take oral medications, and the sample size was small.

Conclusion: Low-dose quetiapine and haloperidol may be equally effective and safe for controlling delirium symptoms.

Clinical trials registration number: clinicaltrials.gov NCT00954603.

Keywords: delirium, quetiapine, haloperidol, extrapyramidal symptoms

\section{Background}

Delirium is an issue of concern in general hospitals. Depending on the definition, measure used, and population, its prevalence is between $10 \%$ and $42 \% .^{1-3}$ This medical condition is associated with high morbidity $(14.0 \%-25.9 \%),{ }^{4,5}$ such as accidental falls, increased length of stay, ${ }^{6,7}$ and also increased mortality. ${ }^{8-10}$ Delirious behavior (including agitation, delusions, hallucinations, and sleep-wake cycle disturbance) poses major problems for managing this condition and usually needs pharmacotherapy.

Several lines of evidence suggest that delirium may result from various neurotransmitter abnormalities, including dopamine and serotonin dysregulation. ${ }^{11}$ Together with the specific treatment for underlying diseases, antipsychotic medications are commonly
Correspondence: Narong Maneeton Department of Psychiatry, Faculty I 10 Intawaroros Road, Sriphum, Amphur Muang, Chiang Mai 50200, Thailand

Tel +66 $53945422 ;+66866720676$

Fax +66 53945426

Email nmaneeto@med.cmu.ac.th 
used to control delirium symptoms. Due to its short half-life, low anticholinergic effects, and little sedation, haloperidol is the treatment of choice for delirium. ${ }^{12}$ However, a major limitation of this agent is extrapyramidal symptoms. In addition, due to the lack of randomized, placebo-controlled trial, its efficacy on delirium symptoms may not be fully supported. Other atypical antipsychotic medications are, therefore, considered as alternative choices for this medical condition. ${ }^{13,14}$

Quetiapine is an atypical antipsychotic medication effective for schizophrenia, bipolar disorder, and major depressive disorder. ${ }^{15-18}$ Recent reports suggest its safety and efficacy for delirium symptoms. ${ }^{19-21}$ Several lines of evidence suggest that atypical antipsychotics are effective and safe for behavioral disturbance associated with delirium. ${ }^{16,19-23}$ Although the findings of a double-blind, randomized, placebo-controlled trial of quetiapine suggest its efficacy on the noncognitive aspect of delirium, ${ }^{24}$ there has been no head-to-head comparison between quetiapine and haloperidol, a gold standard for the treatment of delirious behavior. We, therefore, proposed to carry out a randomized-controlled trial to compare the efficacy and the safety of quetiapine and haloperidol for delirium symptoms. In this study, we hypothesized that quetiapine was as effective as but more tolerable than haloperidol in delirious patients hospitalized in a general hospital.

\section{Methods}

\section{Study design and setting}

The study was approved and monitored by the Ethics Committee of the Faculty of Medicine, Chiang Mai University. Prior to participating in the study, a first-degree relative or legal guardian gave written informed consent after the study details had been fully explained. After the remission of delirium, the same process was repeated to obtain written informed consent directly from each participant. The study protocol was registered with its ClinicalTrials.gov identifier: NCT00954603.

This 7-day prospective, double-blind, flexible dose, randomized controlled trial study was conducted from June 2009 to April 2011 at Chiang Mai University Hospital, a tertiary care setting in northern Thailand.

\section{Selection criteria}

All inpatients presumed to have delirium and needing consultation-liaison services from the psychiatric department were evaluated. Male and female patients were included if they were aged 18-75 years old, and met the diagnostic criteria for delirium as defined by the
Diagnostic and Statistical Manual of Mental Disorders, 4th edition, text revision (DSM-IV-TR). ${ }^{25}$ Since the Confusion Assessment Method (CAM) is a measure with high sensitivity (91\%-97\%) and specificity (85\%-94\%) for the detection of delirium, it was used to confirm the diagnosis. ${ }^{26-28}$ Exclusion criteria were substance-induced delirium (eg, alcohol-withdrawal delirium), known allergy or intolerance to quetiapine or haloperidol, pregnancy or breast feeding, being on an antipsychotic medication, and renal or hepatic failure. Discontinuation criteria included consent withdrawal, safety/efficacy reasons decided by the primary physician, transferring to other hospitals, not being able or allowed to take oral medications, hospital discharges, and receiving other antipsychotic medications. No patients or their relatives received any financial benefit from the participation.

\section{Study medication}

By using a computer-generated randomization system, the participants were randomly assigned in a 1:1 manner to one of two groups (quetiapine or haloperidol). Randomized codes were kept in sealed envelopes and opened after the end of the screening process. The patients, physicians, staff nurses, investigators, and raters were blinded to treatment assignments. The study medication, either a $25 \mathrm{mg}$ tablet of quetiapine or a $0.5 \mathrm{mg}$ tablet of haloperidol, was fully filled and concealed in an identical capsule..$^{13,29,30}$

We orally administered a flexible dose of quetiapine (25-100 mg/day) or haloperidol (0.5-2.0 mg/day) before bedtime and as needed. We adjusted the doses based on the clinical safety, sleepiness, and calmness as measured by the DRS-R-98. For all participants, we started the study medication by giving one capsule orally at bedtime and giving one more capsule every 2-3 hours for agitation. The maximum dose was four capsules per 24 hours. Other psychotropic medications, including benzodiazepines, were prohibited.

\section{Outcome measures}

The measure used for daily assessment was the Delirium Rating Scale-revised-98 (DRS-R-98). ${ }^{31}$ The DRS-R-98 noncognitive (items 1-8) and cognitive (items 9-13) subscale scores were also computed. ${ }^{24}$ The response and remission rates were defined as a reduction of the DRSR-98 severity score from its baseline for $50 \%$ or more and a DRS-R-98 severity score of 12 or less without relapse. ${ }^{14,32}$ The total sleep time per day was recorded daily. The Clinical Global Impression-Improvement (CGI-I) ${ }^{33}$ and the Modified (nine-item) Simpson-Angus Scale (MSAS) 
were applied daily. The primary outcome was the DRSR-98 severity score. ${ }^{27,31}$ Secondary outcomes included the DRS-R-98 noncognitive and cognitive subscale scores, the response rate, remission rate, the total time of sleep, and the CGI-I scores. ${ }^{33}$ At the study's conclusion, extrapyramidal side effects were assessed by using the MSAS. The MSAS is a 5-point scale of nine items (arm dropping, shoulder shaking, elbow rigidity, wrist rigidity, leg pendulousness, head dropping, glabellar tap, tremor, and salivation). Scores are: $0=$ normal; $1=$ slightly; $2=$ moderate; $3=$ marked $4=$ extreme; and $9=$ not ratable. The maximum score is 81 points. For patient safety, the item of gait stability was excluded from the original ten-item Simpson-Angus Scale. ${ }^{34}$ Patients were also assessed for possible adverse events (including any change in concurrent illnesses or new illness) either observed by the investigators, relatives, clinical staff, or self-report.

The investigator (BM) applied all measures and collected relevant data, including total sleep time daily and consecutively for seven days in the evening ( $5 \mathrm{pm}-10 \mathrm{pm})$.

\section{Other safeguards}

Based on a surgical sieve mnemonic of "IWATCHDEATH," each participant received clinical and pathological examination to identify the possible causes of delirium: $\mathrm{I}=$ infections; $\mathrm{W}=$ withdrawal; $\mathrm{A}=$ acute metabolic; $\mathrm{T}=$ toxins drugs; $\mathrm{C}=$ central nervous system (CNS) pathology; $\mathrm{H}=$ hypoxia; $\mathrm{D}=$ deficiencies; $\mathrm{E}=$ endocrine; $\mathrm{A}=$ acute vascular; $\mathrm{T}=$ trauma; $\mathrm{H}=$ heavy metals; and other causes. ${ }^{35}$ This approach was discussed with the primary physician and clinical staff to provide necessary medical management for the underlying diseases of delirium. Primary physicians were responsible for evaluating the clinical safety, laboratory tests, vital signs, electrocardiograms, and physical examination findings. Each participant received appropriate environmental manipulations for delirium, including noise control, light intensity, reassurance, and stimulus modification. ${ }^{12}$

\section{Statistical analysis}

The sample size calculation was conducted to determine an $80 \%$ power in demonstrating a significant difference in efficacy between quetiapine and haloperidol. For a power of $95 \%$ and a 0.05 confidence interval (CI), a sample of 34 per treatment group was needed to detect a mean (standard deviation [SD]) difference of 5 (5.6) points assessed by using the Delirium Rating Scale-revised-98 (DRS-R-98). ${ }^{31}$ We therefore planned to randomize a sample of 35 per group.
The efficacy differences between groups were analyzed on an intention-to-treat basis by including the data obtained from all randomized patients who received at least one dose of medication and had at least one post-randomized assessment. The safety analyses included all subjects who received at least one dose of the study medication.

We compared the demographic data and clinical characteristics by using the chi-square test or Fisher's exact test for categorical variables, and the Mann-Whitney $U$ test or the Student $t$-test for ordinal and interval variables, respectively. The DRS-R-98 severity scores, noncognitive and cognitive subscale scores, clinical global impressionimprovement, and the total time of sleep, assessed daily, were analyzed by using the mixed model for repeated measurements (MMRM), a valid choice of statistical methodology for primary analyses. ${ }^{36}$ All treatment effects were analyzed to assess the group differences at each time point. The number of day treatments, as a controlled parameter, was added to the model. An association was considered statistically significant if the $P$-value was below 0.05. All reported $P$-values were two-sided. No correction was made for multiple comparisons. Betweengroup differences on the MSAS scores obtained at the study end were analyzed by using the Mann-Whitney $U$ Test. All analyses were performed using STATA, version 11.0 (StataCorp LP, College Station, TX, USA).

\section{Results}

Between June 2009 and April 2011, 408 patients were screened to recruit 52 patients for this study. Reasons for exclusion were: alcohol withdrawal delirium; receiving antipsychotic medication prior to the consultation; patient age of $<18$ years or $>75$ years; disallowance by the primary physician; renal or hepatic failure; inability to communicate with the patient; hypoactive delirium; inability to obtain consent; seizure; and disallowance for oral medication. Figure 1 shows the study flow. The demographic and clinical characteristics obtained at baseline were not significantly different between groups (Table 1).

The mean (SD) age was 56.8 (11.8) years (range 30-75). Fourteen patients $(26.9 \%)$ were over the age of 65 . Approximately two-thirds were male. More than half of the patients had fewer than 6 years of education. Physical diseases were various, such as cancer with emphysema thoracic, aortic aneurysm with complications, necrotizing fasciitis with complications, or subdural hematoma with complications. Many participants had a number of medical comorbidities, mainly cancer with complications $(38.5 \%)$, soft tissue and 


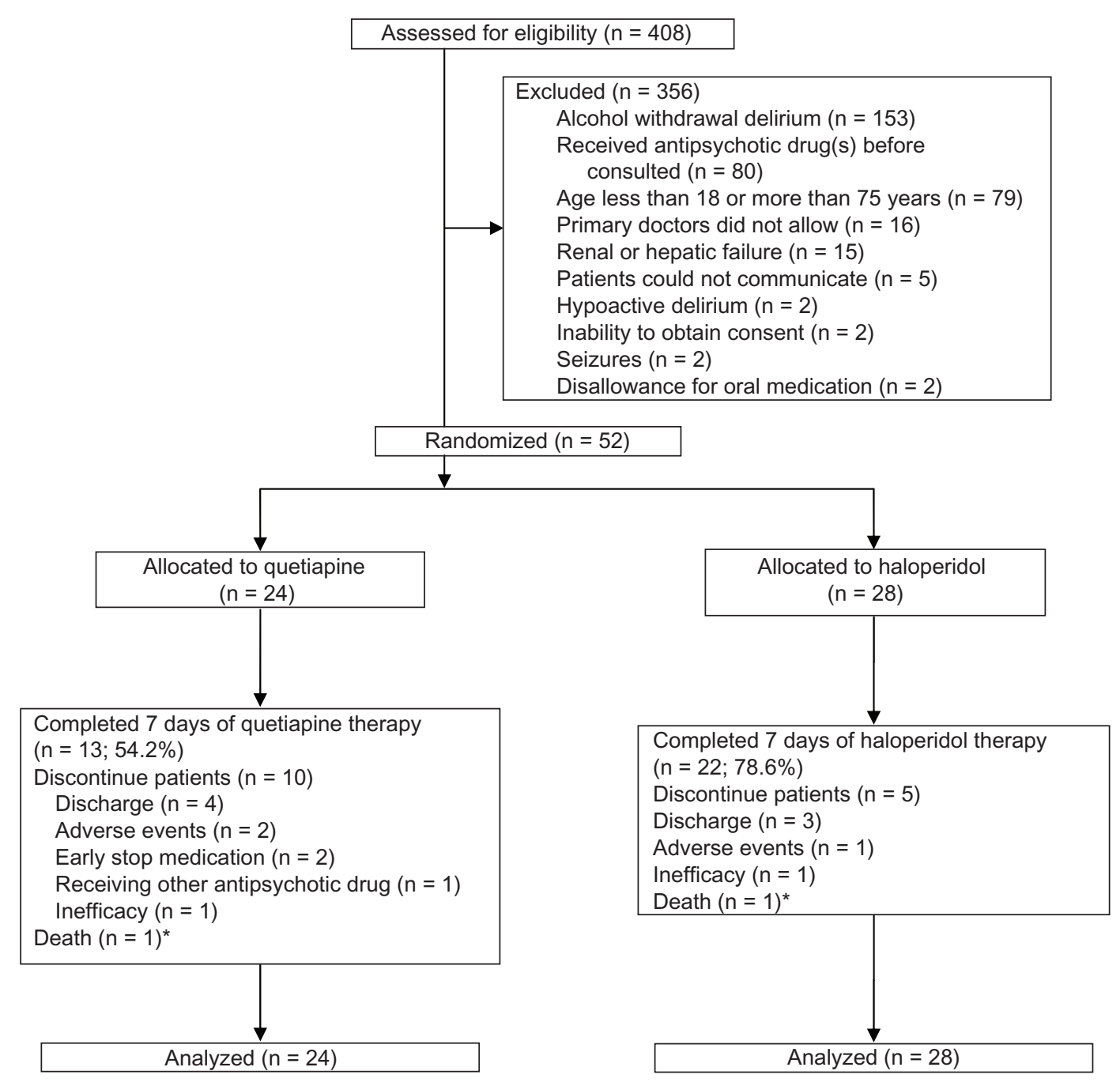

Figure I Flow diagram for the study enrollment and completion of delirious patients. Note: *The cause of death was related to underlying malignancy with sepsis.

bone injury with complications $(36.5 \%)$, cardiovascular disease with complications (13.5\%), and severe infections (11.5\%). Most patients had approximately five to six possible causes of delirium. The numbers of possible causes of delirium were not significantly different between groups. Common causes of delirium included infection (eg, sepsis, emphysema thoracic, opportunistic infection in human immunodeficiency virus patients, and urinary tract infection), malnutrition/deficiency, and fluid-electrolyte imbalance. Twenty-four and 28 participants randomly received quetiapine and haloperidol, respectively. Thirteen quetiapine- and 22 haloperidol-treated patients completed the study (Figure 1). From days 1-7, the mean (SD) daily doses of quetiapine and haloperidol were $67.6(9.7) \mathrm{mg} /$ day and $0.8(0.3) \mathrm{mg} /$ day, respectively. Accumulative adjusted chlorpromazine equivalent doses for the quetiapine and haloperidol groups were 226.8 (67.6) $\mathrm{mg}$ and 286.9 (115.6) $\mathrm{mg}$, respectively $(P=0.09)$.

\section{Efficacy of quetiapine and haloperidol}

The mean (SD) DRS-R-98 severity score of 29.4 (4.5) and the mean (SD) Clinical Global Impression-Severity (CGI-S) score of $6.1(0.8)$ suggested that the participants had severe delirium. Based on the adjusted mixed effects linear regression model, means (SDs) of the decreased DRS-R-98 severity scores over the 7-day trial period were -22.9 (6.9) for the quetiapine group and -21.7 (6.7) for the haloperidol group $(P=0.59)$ (Table 2 and Figure 2).

In addition, means (SDs) of the decreased DRS-R-98 noncognitive and cognitive subscale scores were also not significantly different between groups [quetiapine versus 
Table I Baseline characteristics of patients in the sample

\begin{tabular}{|c|c|c|c|c|}
\hline Characteristic & Total sample $(n=52)$ & Quetiapine $(n=24)$ & Haloperidol $(n=28)$ & $P$-value \\
\hline Age, mean (SD), year & $56.8(11.8)$ & $56.6(12.0)$ & $57.0(11.9)$ & 0.90 \\
\hline Male, number $(\%)$ & $35(67.3)$ & $15(62.5)$ & $20(7 \mathrm{I} .4)$ & 0.49 \\
\hline \multicolumn{5}{|l|}{ Education, number (\%) } \\
\hline Fewer than 6 years & $30(57.7)$ & $13(54.2)$ & $17(60.7)$ & \multirow[t]{5}{*}{0.98} \\
\hline At least 6 years & $7(13.5)$ & $4(16.7)$ & $3(10.7)$ & \\
\hline $6-9$ years & $2(3.8)$ & I (4.2) & I (3.6) & \\
\hline $10-12$ years & $7(\mid 3.5)$ & $3(12.5)$ & $4(14.3)$ & \\
\hline 13 years or more & $6(11.5)$ & $3(12.5)$ & $3(10.7)$ & \\
\hline \multicolumn{5}{|l|}{ Principal diagnosis, number (\%) } \\
\hline Cancer with complications & $20(38.5)$ & $10(4 I .7)$ & $10(35.7)$ & \multirow[t]{4}{*}{0.77} \\
\hline Soft tissue and bone injury with complications & $19(36.5)$ & $7(29.2)$ & $12(42.9)$ & \\
\hline Cardiovascular with complications & $7(13.5)$ & $4(16.7)$ & $3(10.7)$ & \\
\hline Severe infections & $6(11.5)$ & $3(12.5)$ & $3(10.7)$ & \\
\hline \multicolumn{5}{|l|}{ Possible causes of delirium, number (\%) } \\
\hline Infection & $42(80.8)$ & $17(70.8)$ & $25(89.3)$ & 0.16 \\
\hline Fluid-electrolyte imbalance & $39(75.0)$ & $19(79.2)$ & $20(71.4)$ & 0.52 \\
\hline Trauma & $33(63.5)$ & $14(58.3)$ & $19(67.9)$ & 0.47 \\
\hline CNS pathology & $23(44.2)$ & II (45.8) & $12(42.9)$ & 0.83 \\
\hline Hypoxia & $32(61.5)$ & $14(58.3)$ & $18(64.3)$ & 0.66 \\
\hline Malnutrition or deficiency & $40(76.9)$ & $17(70.8)$ & $23(82.1)$ & 0.34 \\
\hline Disorders of the endocrine system & II (2I.2) & $4(16.7)$ & $7(25.0)$ & 0.46 \\
\hline Acute hemodynamic change & $18(34.6)$ & $7(29.2)$ & II (39.3) & 0.44 \\
\hline Toxin or drugs & $21(40.4)$ & $10(41.7)$ & II (39.3) & 0.86 \\
\hline Amitriptyline & $8(15.4)$ & $6(25.0)$ & $2(7.1)$ & 0.12 \\
\hline Tramadol & $3(5.8)$ & $2(8.3)$ & I (3.6) & 0.59 \\
\hline Morphine & $4(7.7)$ & $2(8.3)$ & $2(7.1)$ & 1.00 \\
\hline Steroid & $2(3.8)$ & $2(8.3)$ & $0(0)$ & 0.21 \\
\hline Anticholinergic drug & I (I.9) & $0(0)$ & I (3.6) & 1.00 \\
\hline Baclofen & $\mathrm{I}(1.9)$ & $0(0)$ & I (3.6) & 1.00 \\
\hline Chemotherapy (ifosfamide) & I (1.9) & $\mathrm{I}(4.2)$ & $0(0)$ & 0.46 \\
\hline Total numbers of drug used, mean (SD) & $0.4(0.7)$ & $0.5(0.9)$ & $0.3(0.5)$ & 0.28 \\
\hline Others & $29(55.8)$ & $13(54.2)$ & $16(57.1)$ & 0.83 \\
\hline Total possible causes of delirium, mean (SD) & $5.6(1.6)$ & $5.3(1.5)$ & $5.8(1.6)$ & 0.25 \\
\hline Duration (days) of delirium before enrolled, mean (SD) & $3.1(2.7)$ & $3.3(2.5)$ & $2.9(2.8)$ & 0.16 \\
\hline Baseline DRS-R-98 scores, SD & $29.4(4.5)$ & $29.0(4.4)$ & $29.7(4.6)$ & 0.23 \\
\hline CGI-S score, SD & $6.1(0.8)$ & $6.0(0.8)$ & $6.1(0.8)$ & 0.64 \\
\hline Baseline total sleep time (hours), SD & $1.5(2.2)$ & $2.0(2.7)$ & I.I (I.7) & 0.26 \\
\hline Baseline MSAS, SDa & $0.2(0.7)$ & $0.1(0.5)$ & $0.2(0.8)$ & 0.89 \\
\hline
\end{tabular}

Note: aSome patients had prior movement disorder from Parkinson's disease.

Abbreviations: SD, standard deviation; DRS-R-98, Delirium Rating Scale-revised-98; CGI-S, CGI scale; MSAS, Modified (nine-item) Simpson-Angus Scale; CNS, central nervous system.

haloperidol: -16.9 (5.5) versus -15.8 (4.7); $P=0.54$ and -6.0 (3.2) versus -5.8 (3.6); $P=0.89$, respectively] (Table 2, Figure 3 and 4).

At the end point, means (SDs) of the CGI-I scores were also not significantly different between groups $(P=0.96)$ (Table 2).

\section{Total sleep time}

Over the trial period, the total sleep times (hours) increased for means (SDs) of 6.5 (3.0) for the quetiapine group and 6.1 (3.4) for the haloperidol group ( $P=0.74)$ (Table 2 and Figure 5).

\section{Rate of improvement}

At the end of the study, the response rates defined as above for quetiapine $(79.2 \%)$ and haloperidol (78.6\%) were not significantly different $(P=0.97)$. The remission rates defined above were also not significantly different between groups (75.0\% for quetiapine and $67.9 \%$ for haloperidol; $P=0.96$ ). Mean (SD) times to response for quetiapine and haloperidol were $1.7(0.1)$ days and $1.9(1.6)$ days, respectively $(P=0.51)$. Times to first response of delirium were not significantly different between groups with a hazard ratio (HR) of 1.18 (95\% CI; 0.62-2.25, $P=0.61$ ) (Figure 6). Mean (SD) times 
Table 2 Mean difference of scoring between day 7 and baseline

\begin{tabular}{llll}
\hline & $\begin{array}{l}\text { Quetiapine } \\
\text { Mean } \pm \text { SD } \\
(95 \% \mathbf{C l})\end{array}$ & $\begin{array}{l}\text { Haloperidol } \\
\text { Mean } \pm \text { SD } \\
(95 \% \mathbf{C l})\end{array}$ & P-value \\
\hline Delirium rating & $-22.9 \pm 6.9$ & $-21.7 \pm 6.7$ & 0.59 \\
scale-revised-98 scores & $(-26.9$ to -19.0$)$ & $(-24.7$ to -18.6$)$ & \\
Noncognitive subscore & $-16.9 \pm 5.5$ & $-15.8 \pm 4.7$ & 0.54 \\
& $(-20.1$ to -13.7$)$ & $(-18.0$ to -13.7$)$ & \\
Cognitive subscore & $-6.0 \pm 3.2$ & $-5.8 \pm 3.6$ & 0.89 \\
& $(-7.9$ to -4.1$)$ & $(-7.5$ to -4.2$)$ & \\
Clinical global & $-1.1 \pm 1.0$ & $-1.2 \pm 1.4$ & 0.96 \\
impression, & $(-1.7$ to -0.6$)$ & $(-1.8$ to -0.5$)$ & \\
improvement & $6.5 \pm 3.0$ & $6.1 \pm 3.4$ & 0.74 \\
Sleep time (hours) & $(4.8$ to 8.2$)$ & $(4.6$ to 7.7$)$ & \\
\hline
\end{tabular}

Abbreviations: SD, standard deviation; $\mathrm{Cl}$, confidence interval.

to remission for the quetiapine and haloperidol groups were 2.6 (1.9) days and $1.8(1.5)$ days, respectively $(P=0.14)$. Times to first remission of delirium were not significantly different between groups with a HR of 1.15 (95\% CI; $0.6-2.19, P=0.68$ ) (Figure 7).

\section{Tolerability}

At the study end, means (SDs) of the MSAS scores were $0.3(0.7)$ for the quetiapine group and 0.3 (1.1) for the haloperidol group $(P=0.51)$. Over the trial period, two patients with malignancy (one in the haloperidol group and another one in the quetiapine group) died. The causes of deaths were underlying malignancy with sepsis, which were not related to the trial medications. Table 3 shows the adverse events reported by the patients and/or collateral sources.

\section{Withdrawals from the study}

The withdrawal rate due to all reasons during the entire study was $32.7 \%$ (Figure 1). The reasons included discharge with approval (two quetiapine and three haloperidol patients) and discharge against advice (two quetiapine patients). Two quetiapine-treated patients and one haloperidol-treated patient were withdrawn, due to adverse drug reactions (one rash and one seizure in the quetiapine group and one atrioventricular block in the haloperidol group). Of the quetiapine group, two patients needed preoperative nil by mouth, and one patient received a haloperidol injection ordered by his primary physician (Figure 1).

\section{Discussion}

To our knowledge, this is the first head-to-head, doubleblind, randomized controlled trial comparing the efficacy and safety between quetiapine and haloperidol in controlling delirium symptoms caused by multiple etiologies. The present findings appear to support the equieffectiveness of quetiapine and haloperidol in decreasing delirious behavior. Times to response and remission were also comparable between groups. Compared with low-dose haloperidol, we did not find that the fewer extrapyramidal side effects

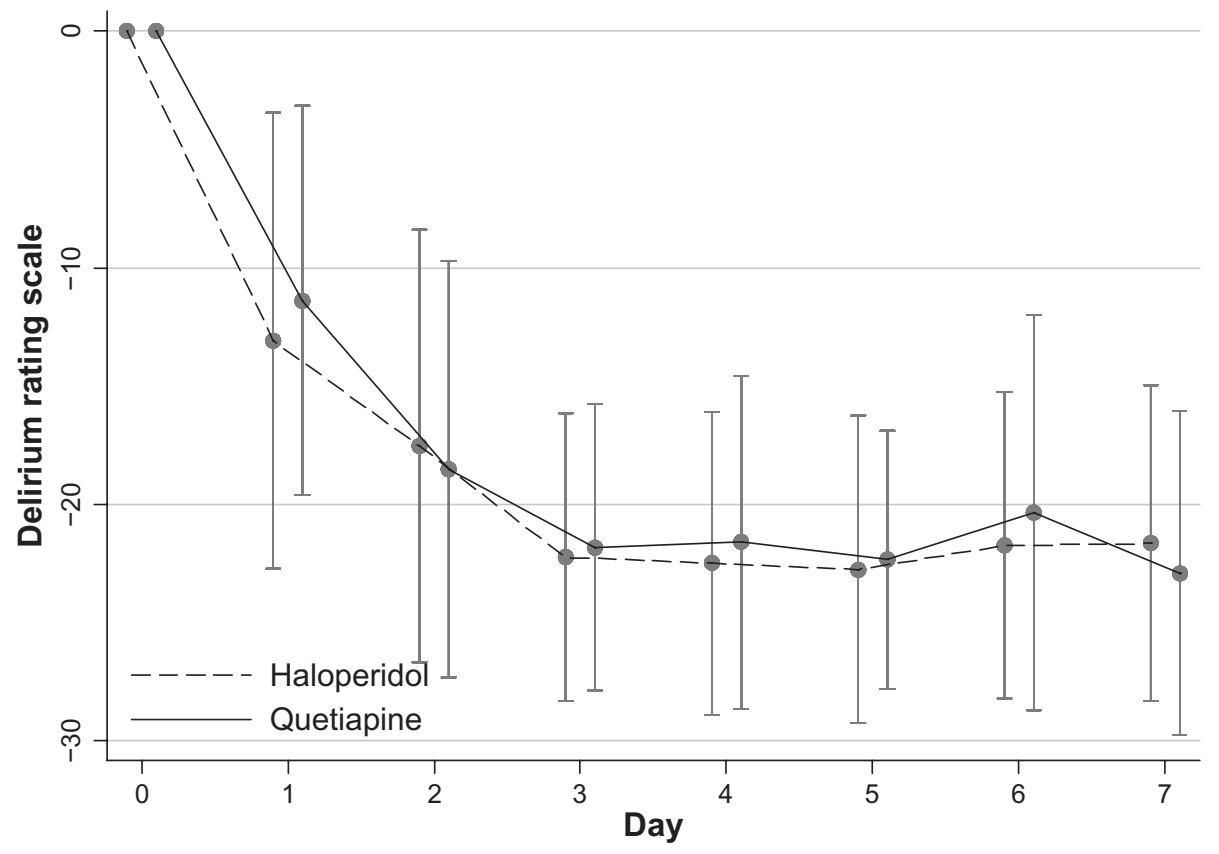

Figure 2 Mean difference of DRS-R-98 severity score from baseline over time after treatment with quetiapine or haloperidol groups (ITT population). Abbreviations: DRS-R-98 severity score, Delirium Rating Scale-Revised-98 severity score; ITT, intent-to-treat analysis. 


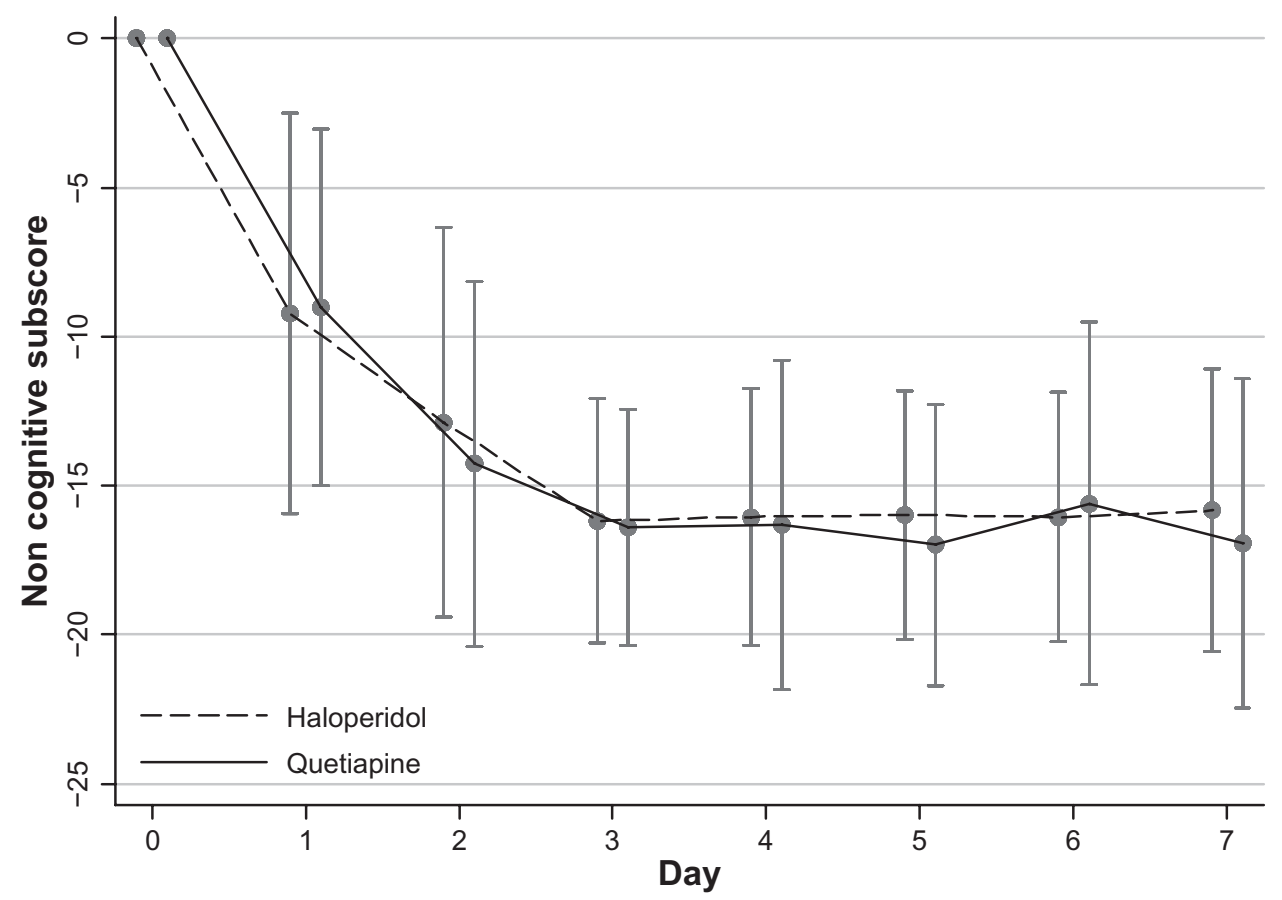

Figure 3 Mean difference of DRS-R-98 noncognitive subscale scores from baseline over time after treatment with quetiapine or haloperidol groups (ITT population). Abbreviations: DRS-R-98 noncognitive subscale scores, Delirium Rating Scale-Revised-98 noncognitive subscale scores; ITT, intent-to-treat analysis.

of quetiapine found in schizophrenia and bipolar patients caused any benefit for individuals with delirium. Although hypersomnia was more common in quetiapine-treated patients, the total sleep times were not much different between the treatment groups.

The results of this study are consistent with previous findings. For delirium severity, our study found the same pattern of DRS-R-98 effects as those of other studies. ${ }^{13,20}$ The times to response and remission from delirium were equal in both active drugs and shorter than those of previous studies. This was due to the high quality of frequency of clinical and research contact. Most of the studies showed that the resolution time (mean [SD]) of quetiapine was in the range of 4.8-7.4 days. ${ }^{19,20,37-39}$ The average times to response

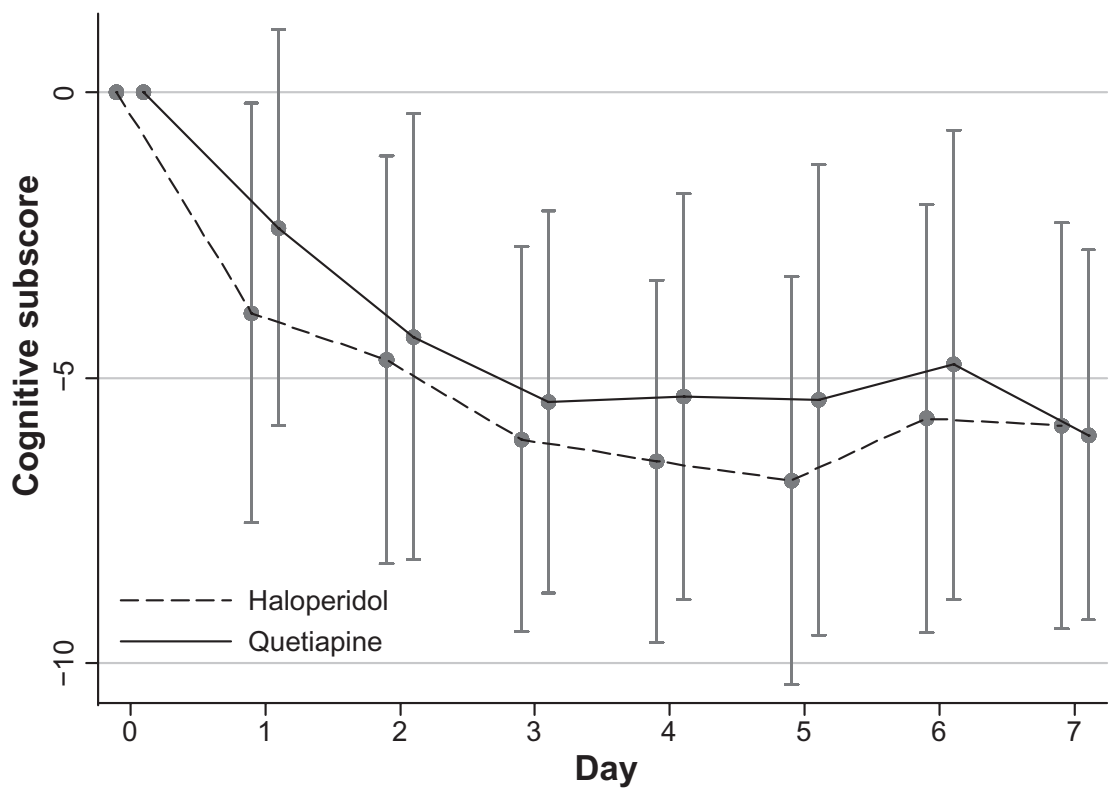

Figure 4 Mean difference of DRS-R-98 cognitive subscale scores from baseline over time after treatment with quetiapine or haloperidol groups (ITT population). Abbreviations: DRS-R-98 cognitive subscale scores, Delirium Rating Scale-Revised-98 cognitive subscale scores; ITT, intent-to-treat analysis. 


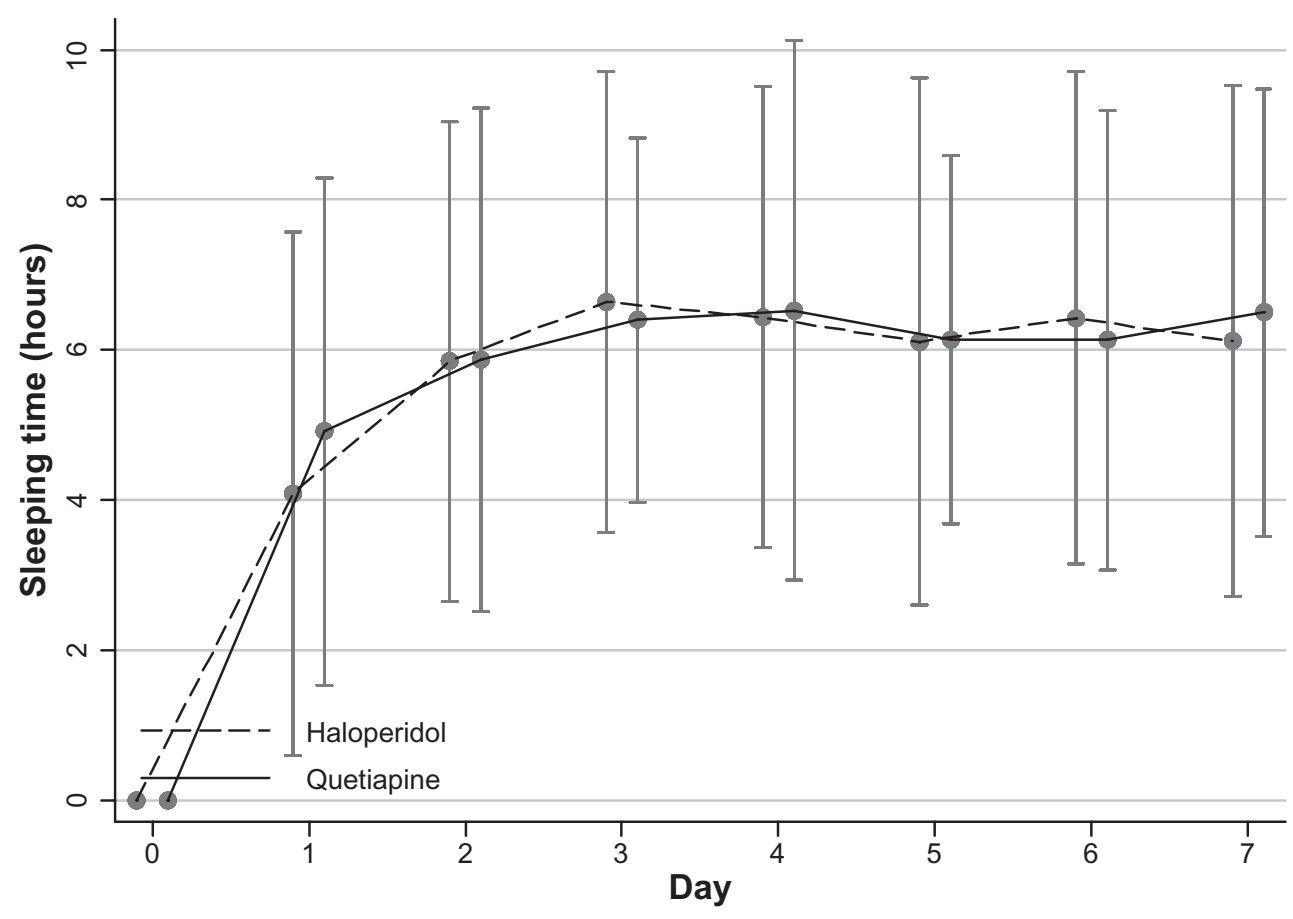

Figure 5 Mean difference of total sleep time (hours) from baseline over time after treatment with quetiapine or haloperidol groups (ITT population). Abbreviation: ITT, intent-to-treat analysis.

and remission in the quetiapine group in this study were 1.7 (0.1) day and 2.6 (1.9) days, respectively. The differences of those findings may result from the low doses of quetiapine. Since quetiapine has moderate anticholinergic effects, ${ }^{40}$ in high doses it may be a cause of delayed improvement.

In this study, the average dose of antipsychotics in the management for delirium was relatively low compared with those applied in previous studies. Several studies demonstrated that the optimal doses of haloperidol and quetiapine for delirious patients may be in the ranges of $0.25-10.0 \mathrm{mg} /$ day $^{13,22,41-45}$ and $44.9-127.1 \mathrm{mg} /$ day, respectively. ${ }^{19,20,37-39}$ However, another recent study ${ }^{13,24}$ indicated that low dose quetiapine (25.0-40.0 mg/day), similar to this study, was also effective for the treatment of delirium. The small

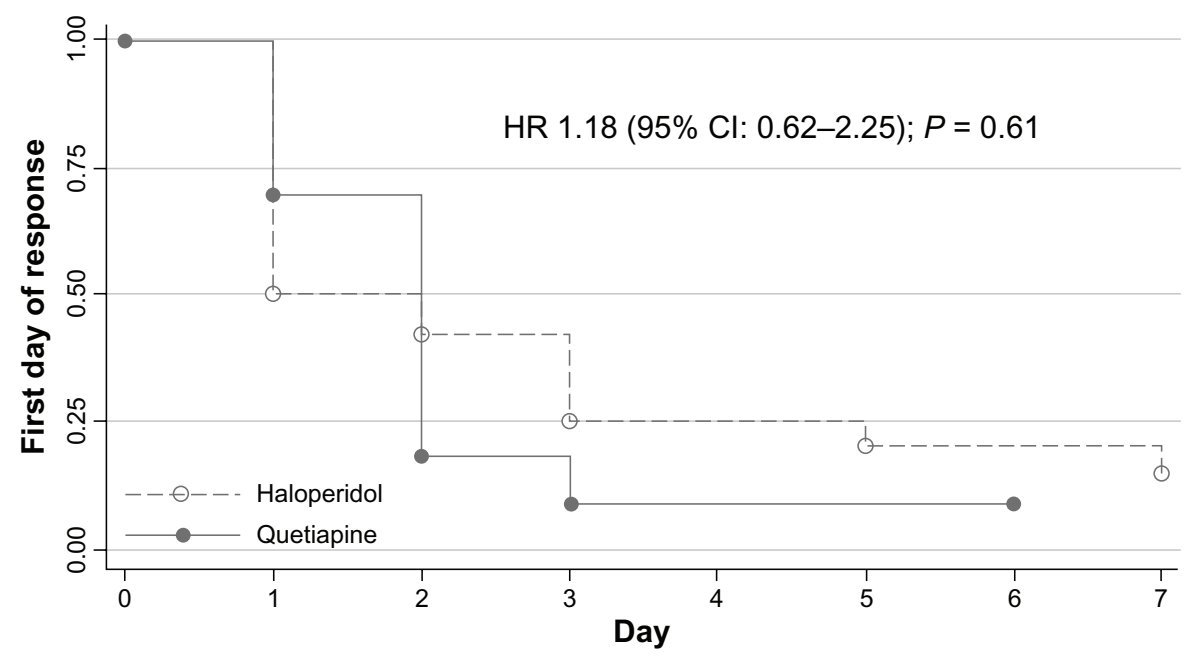

Figure 6 Kaplan-Meier survival estimates of first-day response in delirious patients. Abbreviations: $\mathrm{HR}$, hazard ratio; $\mathrm{Cl}$, confidence interval. 


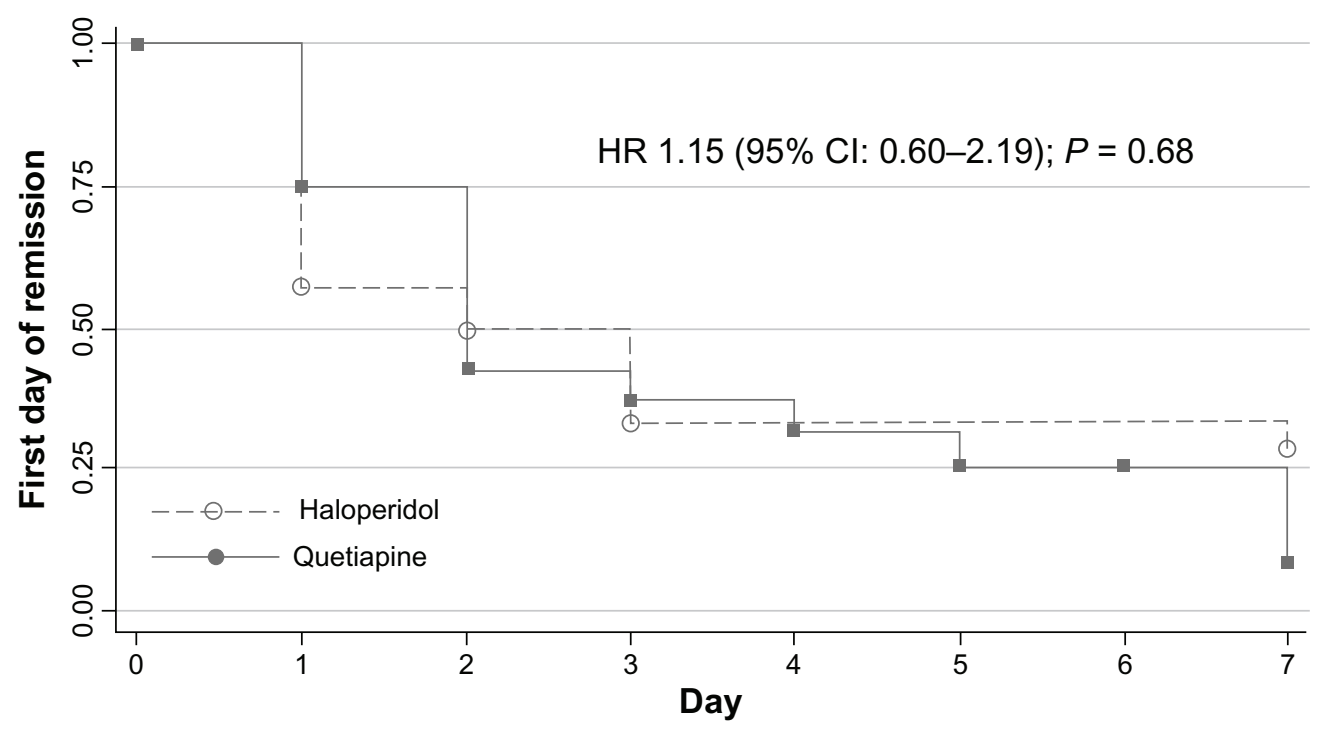

Figure 7 Kaplan-Meier survival estimates of first-day remission in delirious patients. Abbreviations: $\mathrm{HR}$, hazard ratio; $\mathrm{Cl}$, confidence interval.

body size of Asian patients might be a reason for a low-dose quetiapine and haloperidol administration in this study.

Extrapyramidal symptoms associated with antipsychotic medications, especially haloperidol, has been a major concern for the pharmacotherapy of delirium. A daily dose of 5-15 mg of haloperidol may cause extrapyramidal symptoms in 19\%-29\% patients with delirium, which is greater than the incidence in those taking atypical antipsychotics. ${ }^{44-48}$ The low incidence of extrapyramidal symptoms in this study might be due to the administration of haloperidol at low doses. In our findings, other adverse events were also comparable. Since delirious symptoms have a common manifestation with side effects related to antipsychotic medications, it may be difficult to identify whether these symptoms were the side effects of the antipsychotic medications.

Having a sample mainly composed of young adult subjects ( $<65$ years), hospitalized in a general hospital setting, allowed for careful protocol administration in a group of patients with less confounding factors than a more elderly sample.

Table 3 Summary of adverse events seen in the study sample

\begin{tabular}{llll}
\hline Side effects & $\begin{array}{l}\text { Quetiapine } \\
\text { group } \\
\text { number (\%) }\end{array}$ & $\begin{array}{l}\text { Haloperidol } \\
\text { group } \\
\text { number (\%) }\end{array}$ & P-value \\
\hline Hypersomnia & $\mathrm{I} 0(4 \mathrm{I} .7)$ & $8(28.6)$ & 0.32 \\
Tremor & $0(0)$ & $\mathrm{I}(3.6)$ & 1.00 \\
Nightmare & $\mathrm{I}(4.2)$ & $0(0)$ & 0.46 \\
Rash & $\mathrm{I}(4.2)$ & $\mathrm{I}(3.6)$ & $\mathrm{I} .00$ \\
Akathisia & $0(0)$ & $\mathrm{I}(3.6)$ & 1.00 \\
Tics & $0(0)$ & $\mathrm{I}(3.6)$ & 1.00 \\
\hline
\end{tabular}

Younger groups tend to yield better generalizability for these reasons. While an even bigger sample would perhaps shed more light on potential differences of pharmacological effects, this study appeared to achieve high power meaningful results in a group which is difficult to study. This study used an efficacy measure (DRS-R-98) daily for 7 days with success, allowing for appropriate frequency of data in a rapidly fluctuating condition. The logistics of daily measurement are a challenge in trials methodology. Another strength of this study is the comparison of extrapyramidal side effects between groups.

This study has some limitations. First, as vulnerable subjects, the delirious patients aged over 75 and severely ill, eg, with renal or hepatic failure, were excluded. Most of the patients were under the age of 65 . Vulnerable subjects are protocol difficulties, which will always prove a bête noire in design. Second, patients with acute CNS pathology and other cognitive disorders, including dementia, were not excluded. Including these patients might cause the inaccuracy of delirium measurement, especially in the DRS-R-98 cognitive subscales. Giving more attention on the DRS-R-98 noncognitive subscales may solve these difficulties. Third, since mean (SD) of time between delirium being first identified and randomization [3.1 days (2.7)] was quite long, the delirium in some patients in each group might be resolved by itself. Fourth, all subjects received only active agents. There was still no placebo control group, and many side effects were subjectively reported. Fifth, the lack of differences of many outcomes and adverse effects, in particularly the extrapyramidal side effect, might be caused by the small sample size. Finally, although the sleeping time 
and the DRS-R-98 sleep-wake cycle subscale were evaluated, their qualities were not assessed.

\section{Conclusion}

Low doses of both quetiapine and haloperidol are equally effective and safe for the management of behavioral disturbance in delirious patients, given together with environmental manipulation.

\section{Acknowledgments}

We thank Stephen D Martin of Brandon Lane Neuropsychiatry Clinic, Durham, United Kingdom for his help with the project, and Paula T Trzepacz of Indiana University School of Medicine and Lilly Research Laboratories, who granted permission for the use of the DRS-R-98. We also thank R Phuackchantuck of Chiang Mai University for her help with statistical analysis in this project.

\section{Disclosure}

This study was financed by the Faculty of Medicine, Chiang Mai University, Chiang Mai, Thailand, grant number 077/52. The study funders had no role in study design, data collection and analysis, decision to publish, or preparation of the manuscript. NM has received travel reimbursement from GlaxoSmithKline, Pfizer, Janssen-Cilag, and Lundbeck. $\mathrm{BM}$ has received honoraria and/or travel reimbursement from GlaxoSmithKline and Pfizer. MS received honoraria, consultancy fees, research grants, and/or travel reimbursement from AstraZeneca, GlaxoSmithKline, Pfizer, Janssen-Cilag, Johnson \& Johnson, Lundbeck, Thai-Otsuka, Sanofi-Aventis, and Servier Laboratories. KC reports no conflict of interest in this study.

\section{References}

1. Burns A, Gallagley A, Byrne J. Delirium. J Neurol Neurosurg Psychiatry. 2004;75(3):362-367.

2. Maneeton B, Khemawichanurat W, Maneeton N. Consultation-liaison psychiatry in Maharaj Nakorn Chiang Mai Hospital. ASEAN Journal of Psychiatry. 2007;8(2):124-130.

3. Siddiqi N, House AO, Holmes JD. Occurrence and outcome of delirium in medical in-patients: a systematic literature review. Age Ageing. 2006;35(4):350-364.

4. Inouye SK, Rushing JT, Foreman MD, Palmer RM, Pompei P. Does delirium contribute to poor hospital outcomes? A three-site epidemiologic study. J Gen Intern Med. 1998;13(4):234-242.

5. González M, Martínez G, Calderón J, et al. Impact of delirium on short-term mortality in elderly inpatients: a prospective cohort study. Psychosomatics. 2009;50(3):234-238.

6. Lakatos BE, Capasso V, Mitchell MT, et al. Falls in the general hospital: association with delirium, advanced age, and specific surgical procedures. Psychosomatics. 2009;50(3):218-226.

7. Mahoney JE, Palta M, Johnson J, et al. Temporal association between hospitalization and rate of falls after discharge. Arch Intern Med. 2000;160(18):2788-2795.
8. McCusker J, Cole M, Abrahamowicz M, Primeau F, Belzile E. Delirium predicts 12-month mortality. Arch Intern Med. 2002;162(4):457-463.

9. Pisani MA, Kong SY, Kasl SV, Murphy TE, Araujo KL, Van Ness PH. Days of delirium are associated with 1-year mortality in an older intensive care unit population. Am J Respir Crit Care Med. 2009;180(11): 1092-1097.

10. Buurman BM, Hoogerduijn JG, de Haan RJ, et al. Geriatric conditions in acutely hospitalized older patients: prevalence and one-year survival and functional decline. PLoS One. 2011;6(11):e26951.

11. Flacker JM, Lipsitz LA. Neural mechanisms of delirium: current hypotheses and evolving concepts. J Gerontol A Biol Med Sci. 1999;54(6):B239-B246.

12. American Psychiatric Association. Practice guideline for the treatment of patients with delirium. American Psychiatric Association. Am J Psychiatry. 1999;156(Suppl 5):1-20.

13. Grover S, Kumar V, Chakrabarti S. Comparative efficacy study of haloperidol, olanzapine, and risperidone in delirium. J Psychosom Res. 2011;71(4):277-281.

14. Kim SW, Yoo JA, Lee SY, et al. Risperidone versus olanzapine for the treatment of delirium. Hum Psychopharmacol. 2010;25(4):298-302.

15. Srisurapanont M, Maneeton B, Maneeton N. Quetiapine for schizophrenia. Cochrane Database Syst Rev. 2004;(2):CD000967.

16. Vieta E, Locklear J, Günther O, et al. Treatment options for bipolar depression: a systematic review of randomized, controlled trials. J Clin Psychopharmacol. 2010;30(5):579-590.

17. Komossa K, Depping AM, Gaudchau A, Kissling W, Leucht S. Secondgeneration antipsychotics for major depressive disorder and dysthymia. Cochrane Database Syst Rev. 2010;(12):CD008121.

18. Maneeton N, Maneeton B, Srisurapanont M, Martin SD. Quetiapine monotherapy in acute phase for major depressive disorder: a metaanalysis of randomized, placebo-controlled trials. BMC Psychiatry. 2012;12:160.

19. Maneeton B, Maneeton N, Srisurapanont M. An open-label study of quetiapine for delirium. J Med Assoc Thai. 2007;90(10):2158-2163.

20. Lee KU, Won WY, Lee HK, et al. Amisulpride versus quetiapine for the treatment of delirium: a randomized, open prospective study. Int Clin Psychopharmacol. 2005;20(6):311-314.

21. Devlin JW, Roberts RJ, Fong JJ, et al. Efficacy and safety of quetiapine in critically ill patients with delirium: a prospective, multicenter, randomized, double-blind, placebo-controlled pilot study. Crit Care Med. 2010;38(2):419-427.

22. Han CS, Kim YK. A double-blind trial of risperidone and haloperidol for the treatment of delirium. Psychosomatics. 2004;45(4):297-301.

23. Pelland C, Trudel JF. Atypical antipsychotic efficacy and safety in managing delirium: a systematic review and critical analysis. Psychol Neuropsychiatr Vieil. 2009;7(2):109-119. French [with English abstract].

24. Tahir TA, Eeles E, Karapareddy V, et al. A randomized controlled trial of quetiapine versus placebo in the treatment of delirium. J Psychosom Res. 2010;69(5):485-490.

25. American Psychiatric Association. Diagnostic and Statistical Manual of Mental Disorders, 4th ed, text revision. Washington, DC: American Psychiatric Association; 2000.

26. Inouye SK, van Dyck CH, Alessi CA, Balkin S, Siegal AP, Horwitz RI. Clarifying confusion: the confusion assessment method. A new method for detection of delirium. Ann Intern Med. 1990;113(12):941-948.

27. Mitchell AJ. Confusion Assessment Method is the most appropriate tool to quickly detect delirium in hospitalised patients at the bedside. Evid Based Ment Health. 2011;14(1):4.

28. Wei LA, Fearing MA, Sternberg EJ, Inouye SK. The Confusion Assessment Method: a systematic review of current usage. JAm Geriatr Soc. 2008;56(5):823-830.

29. Copolov DL, Link CG, Kowalcyk B. A multicentre, double-blind, randomized comparison of quetiapine (ICI 204,636, 'Seroquel') and haloperidol in schizophrenia. Psychol Med. 2000;30(1):95-105.

30. Woods SW. Chlorpromazine equivalent doses for the newer atypical antipsychotics. J Clin Psychiatry. 2003;64(6):663-667. 
31. Trzepacz PT, Mittal D, Torres R, Kanary K, Norton J, Jimerson N. Validation of the Delirium Rating Scale-revised-98: comparison with the delirium rating scale and the cognitive test for delirium. J Neuropsychiatry Clin Neurosci. 2001;13(2):229-242.

32. Trzepacz PT, Bourne R, Zhang S. Designing clinical trials for the treatment of delirium. J Psychosom Res. 2008;65(3):299-307.

33. Guy W. National Institute of Mental Health. Clinical global impressions (CGI). In: Guy W, editor. The ECDEU Assessment Manual for Psychopharmacology-Revised. Volume DHEW Publ No ADM 76338. Rockville, MD: US Department of Health, Education, and Welfare, NIMH; 1976:218-222.

34. Simpson GM, Angus JW. A rating scale for extrapyramidal side effects. Acta Psychiatr Scand Suppl. 1970;212:11-19.

35. Wise MG, Hilty DM, Cerda GM, Trzepacz PT. Delirium (confusional states). In: Wise MG, Rundell JR, editors. Textbook of consultationliaison psychiatry in the medically ill. American Psychiatric Publishing, Washington, DC; 2002:257-272.

36. Tahir TA, Farewell D, Bisson J. Randomised control trials for delirium: current evidence and statistical methods. J Psychosom Res. 2012;72(1):84-85.

37. Kim KY, Bader GM, Kotlyar V, Gropper D. Treatment of delirium in older adults with quetiapine. J Geriatr Psychiatry Neurol. 2003;16(1): 29-31.

38. Sasaki Y, Matsuyama T, Inoue S, et al. A prospective, open-label, flexible-dose study of quetiapine in the treatment of delirium. J Clin Psychiatry. 2003;64(11):1316-1321.

39. Pae CU, Lee SJ, Lee CU, Lee C, Paik IH. A pilot trial of quetiapine for the treatment of patients with delirium. Hum Psychopharmacol. 2004;19(2):125-127.
40. Miodownik C, Lerner V. Quetiapine: efficacy, tolerability and safety in schizophrenia. Expert Rev Neurother. 2006;6(7):983-992.

41. Kalisvaart KJ, de Jonghe JF, Bogaards MJ, et al. Haloperidol prophylaxis for elderly hip-surgery patients at risk for delirium: a randomized placebo-controlled study. J Am Geriatr Soc. 2005;53(10):1658-1666.

42. Devlin JW, Bhat S, Roberts RJ, Skrobik Y. Current perceptions and practices surrounding the recognition and treatment of delirium in the intensive care unit: a survey of 250 critical care pharmacists from eight states. Ann Pharmacother. 2011;45(10):1217-1229.

43. Sipahimalani A, Masand PS. Olanzapine in the treatment of delirium. Psychosomatics. 1998;39(5):422-430.

44. Skrobik YK, Bergeron N, Dumont M, Gottfried SB. Olanzapine vs haloperidol: treating delirium in a critical care setting. Intensive Care Med. 2004;30(3):444-449.

45. $\mathrm{Hu} \mathrm{H}$, Deng W, Yang H. A prospective random control study comparison of olanzapine and haloperidol in senile delirium. Chongqing Medical Journal. 2004;8:1234-1237.

46. Girard TD, Pandharipande PP, Carson SS, et al. Feasibility, efficacy, and safety of antipsychotics for intensive care unit delirium: the MIND randomized, placebo-controlled trial. Crit Care Med. 2010;38(2): 428-437.

47. Boettger S, Friedlander M, Breitbart W, Passik S. Aripiprazole and haloperidol in the treatment of delirium. Aust N ZJ Psychiatry. 2011;45(6): $477-482$.

48. Rea RS, Battistone S, Fong JJ, Devlin JW. Atypical antipsychotics versus haloperidol for treatment of delirium in acutely ill patients. Pharmacotherapy. 2007;27(4):588-594.
Drug Design, Development and Therapy

\section{Publish your work in this journal}

Drug Design, Development and Therapy is an international, peerreviewed open-access journal that spans the spectrum of drug design and development through to clinical applications. Clinical outcomes, patient safety, and programs for the development and effective, safe, and sustained use of medicines are a feature of the journal, which

\section{Dovepress}

has also been accepted for indexing on PubMed Central. The manuscript management system is completely online and includes a very quick and fair peer-review system, which is all easy to use. Visit http://www.dovepress.com/testimonials.php to read real quotes from published authors. 